\title{
A Review of Irrigation Water Management Research Achievements of JARC
}

\author{
Minda Tadesse* addisu Asefa \\ Department of Irrigation and Water Harvesting Research , Jimma Agricultural research center, \\ PO box 192, Jimma, Ethiopia
}

\begin{abstract}
Crop production in Ethiopia is largely dominated by rain-fed agriculture, which is suffered by climate change, due to occurrence of erratic rain falls. Therefore, it should be supplemented with irrigation; unless it is difficult to supply food for extremely growing country's food demands. To alleviate such problems, Jimma irrigation research departments conducted a number of experiments to improve crop productivity as well as water use efficiency with minimum yield penalty at the expense of water saving at different climatic condition of southwestern Ethiopia. Therefore, the objective of this review is to analyze best research findings and technologies that were checked at different locations. Among promising results, deficit irrigation, inducing moisture stress at different growth stages of crops, supplemental irrigation, integrated use of mulching with deficit irrigation, mineral fertilization (Phosphorous and Nitrogen) vis irrigation, and irrigation scheduling are the major one. Accordingly, optimum yield of maize was reported when it was irrigated at alternate furrow method, is preferably good when irrigation amount is not less than $75 \%$ ETc, which saved about $50 \%$ of water over conventional furrows $100 \%$ ETc. Then the saved water used to irrigate additional piece of land. The other irrigation strategy is skipping irrigation in less sensitive stage of crops, the report comes from Haru ( Gimbi area) indicated that skipping irrigation during initial and late season had minimum impacts on maize yields, with $50 \%$ water saving as compared to all stage irrigated maize. In addition to reducing the amount of water significantly, the cover crop could play significant role in reducing soil evaporation. For instance, the experiment conducted at Haru showed that alternate furrow mulched with plastic mulch provided highest potato yield over non-mulched. Most of time, the fertilizer recommendation made for rain fed agriculture does not work for irrigated agriculture. The full irrigation (100\% ETc) combined with $46 \mathrm{~kg} / \mathrm{ha}$ phosphorous in soybean provided highest yield. However, increasing the amount of phosphorous fertilizer beyond this level did not increase the yield even if the field receives enough moisture. Finally, the future research direction should focus on water saving together with optimized fertilization through liquid water, and integrated with water harvesting in areas with limited water source either physical or economical.
\end{abstract}

Keywords: Deficit Irrigation, Moisture Stress and Irrigation Scheduling

DOI: $10.7176 / \mathrm{JRDM} / 78-01$

Publication date:August $31^{\text {st }} 2021$

\section{Introduction}

The economy of Ethiopia is majorly dependant on agriculture; however, highly affected by frequent recurrent drought, which reduces agricultural production. Even though the southwestern parts of our country endowed with higher annual rainfall, but its spatial and temporal distribution is uneven. From a year total rainfall, about $71 \%$ received during only four months, and the rest during eight months, which is less than reference evapotranspiration. This tells us, necessity of supplemental irrigation during these dry spells. Connection with this, the amount of river water become declined, in addition, most river not physically avail due to topographic barrier or not easily diverted, to overcome this problems farmer use diesel pump to bring water to command areas which require fuel cost.

Having these all problems in mind, generating efficient irrigation water management technologies and practices provided immense merit in improving crop yield and water productivity. In addition it enables us to produce twice or more crops a year, intern safeguard food security in the area. Deficit irrigation is water saving irrigation strategy, in which irrigation water is applied at amounts less than full crop water requirement (good when deficit $<40 \%$ of ET), there by increases water use efficiency. Irrigating crops with $100 \%$ ETc at alternate furrow saves $50 \%$ water and this used for further production (Robel et al., 2019).

Imposing soil moisture stress also has significant impact on crop yield and water productivity. Imposing moisture stress during initial stage and late season had less effect on yield, but moistures stress during flowing stage reduced the yield of crop. Robel et al. (2019) reported that withholding irrigation during development and mid-season stage (tesseling and silking) had greatly reduced the yield and dry biomass by about 35 and $40 \%$, respectively. However, imposing moisture stress during initial and late season stage had less impact on yield.

FAO conducted varies field experiments under varies agro-ecological zones to set the depletion factor of different crops including soybean. They published the depletion factor for humid, sub-humid and semi-arid areas of the world (Allen et al., 1998). However, the value of depletion factor available in FAO paper is more general 
and requires some adjustment to the local condition. Irrigation scheduling is method of determining how much to irrigate and when to irrigate. Most farmers did not know the amount of water to be irrigated and time of irrigation application. For appropriate irrigation scheduling, adjusting soil depletion factor (p) to local condition plays significant role in irrigation scheduling. To validate such results few studies conducted in Ethiopia. Robel et al. (2019) conducted an experiment for three consecutive years at Jimma, with the aim of determining soil moisture depletion level for soybean crop. From the result, higher yield was obtained from recommended FAO treatment. This implies, that more frequent irrigation did not increase the yield rather encouraged the vegetative growth. Therefore, the optimum soil depletion level for soybean was 100ASMDL $(\mathrm{p}=0.5)$ in irrigated agriculture around Jimma zone

This review is intended to provide research findings and practices that generated by Jimma irrigation research department which helps farmers and institution engaged in irrigation works. It also provides general guidance to research and development institutions in irrigation in identifying research priorities and formulating their programmes of research as well as to provide direction to irrigation departments in its awareness creating and promotional work and research and development.

\section{Major Research Achievement}

\subsection{Yield Response of crops to Deficit irrigation}

Deficit irrigation is water saving irrigation strategy used in many parts of the world in which irrigation water is applied at amounts less than full crop water requirement, there by increases water use efficiency (Morison, 2008). It has been argued that the level of irrigation supply under deficit irrigation should be between $60-100 \%$ of ETc. The main objective of deficit irrigation is to save limited water with relatively little impact on yield. The availability of water is not only appeared in semi-raid area only but also in humid area especially during dry period while farmers required to produce twice or more in a year. In southern Ethiopia even if the annual amount of rainfall is abundant, its temporal distribution is erratic. The production of crops during dry period is impossible without irrigation. However, the south-western Ethiopia is mainly characterized by rugged topography; in which much of flowing river is flowing under gorges which makes difficult to lifting water to command areas. Thus, it is costs for withdrawing of river water and often inaccessible to all many farmers at same time. Despite limited water supply the use of surface water practiced quite frequently.

So under such circumstances, adopting water saving strategy is critically important. Regardless of this different research were carried out in Ethiopia to prove the feasibility of deficit irrigation, in particular south west Ethiopia. The feasibility of deficit irrigation was tested for soybean and maize crops at Malko, Jimma zone, the deficit levels were combined with furrow methods (conventional, fixed and alternate) and the experiment was conducted for three consecutive years. From this it was concluded that $100 \%$ ETc conventional furrow provided highest yield as compared to fixed furrows but it recorded lowest water use efficiency. The 50\% ETc fixed furrows greatly reduced the yield of soybean below tolerable level, which is $44 \%$ yield reduction and not economical. Interestingly, both $100 \%$ ETc alternate furrow and conventional furrow $75 \%$ ETc indicated minimum yield loss by saving extra water, especially alternate furrow $100 \%$ ETc saved $50 \%$ irrigation water as compared to conventional $100 \%$ ETc. This saved amount of water is used to irrigate extra unit of land thereby produce additional soybean yield of about $94 \%$ greater as compared to conventional $100 \%$ ETc. Thus, it is advisable to use $100 \%$ ETc alternate furrows in areas with limited water or during dry period even in humid areas, when rain fall is missed for soybean production. Furthermore, regardless of water productivity, both $50 \%$ and 100 ETc alternate furrows recorded the higher water productivity, while the lowest from 100 ETc conventional furrows (Robel et al., 2019). Applying irrigation water throughout the whole season reduced the water productivity.

Also similar positive results have been described for maize. The experiment conducted in Jimma suggested that the irrigation water use for maize could be reduced up to $50 \%$ ETc with limited yield loss. From this study, maximum yield was obtained from conventional furrow as compared to $100 \%$ ETc conventional furrow method. However, $50 \%$ ETc of irrigation applied in fixed furrow method reduced the yield of maize up to $50 \%$ as compared fully irrigated one (JARC,2015). The maximum water use efficiency was obtained from 100\% ETc alternate furrow, which is with soybean crops. But $100 \%$ ETc conventional furrow reduced the water productivity of maize by about $50 \%$ as compared to alternate $100 \%$ ETc. From these experiments we observed that as we increased irrigation water from $50 \%$ to $100 \%$ ETc, the water productivity was linearly decreased both for maize and soybean. We suggest that deficit irrigation accompanied with furrow method would greatly reduce the soybean and maize crop water requirement just by about $50 \%$ (Table 2 ).

Again other similar trials were conducted on different crops (maize, common bean and onion) across various regions and they reported similar results, as moisture level increased the production of the crop will decline (Jonghan and Giovanni, 2009; Simsek et al., 2011; Enciso et al., 2009). The reason why the optimum yield in alternate furrow irrigation is well performing as compared to conventional furrow irrigation system is probably because of a better application efficiency and physiological response associated with alternate furrow 
irrigation (Kang, 2000; Zhang et al., 2000) and less evapotranspiration associated with alternate furrow irrigation (Stone et al., 1979).

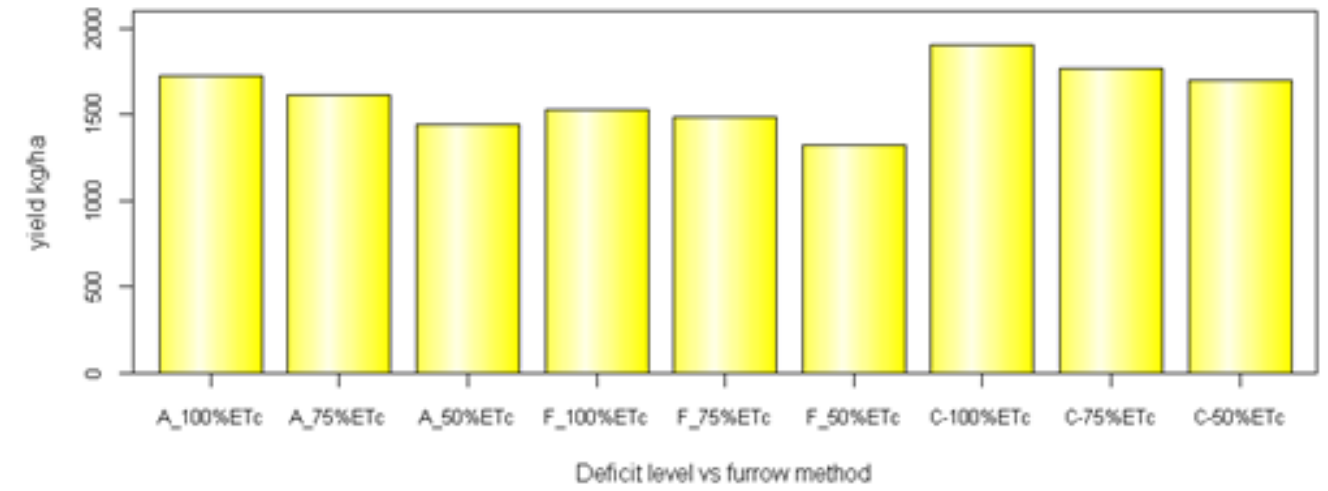

Figure 1. Effect of deficit and furrow irrigation systems on yield

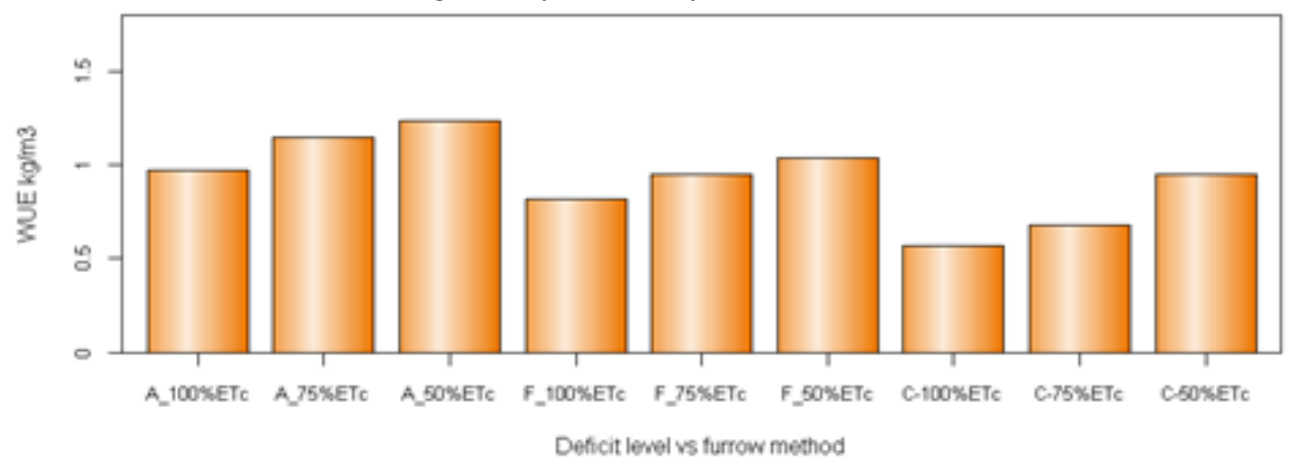

Source: Robel et al., 2019

Figure 2. Effect of deficit and furrow irrigation systems on water productivity

\subsection{Effect moisture stress viz different growth stage on crops yields}

Unlike deficit irrigation, moisture stress is one of strategy of water saving practice in which irrigation is skipped in any of growth stages of crops that is supposed to be less sensitive to drought. Different attempt have been carried out to prove the applicability of moisture stress imposition at any growth stage of varies crops, the ultimate objective of the studies were to identify the most sensitive growth stage of crops as well as severity of the stress. The major factors that forced many farmers to reduce irrigation water are cost of irrigation pumping, inadequate irrigation scheme capacity and limited water resource.

Having these problems in mind, Robel et al., (2019) evaluated the response of maize to moisture stress at different growth stages under prevailing climatic condition of Haru, western Wallaga Zone. From their finding, skipping irrigation at both development and mid-season (tesseling and silking) stage indicated as reduced the yield and dry biomass by about 35 and $40 \%$, respectively.

Similarly, an experiment was conducted on common bean, at Jimma (Malko), with the aim of identifying effect of skipping irrigation in any of its development stage or in combination of stages (Robel et al., 2019). They concluded that higher yield and dry biomass was obtained from fully irrigated treatment, but lower water productivity. However, skipping irrigation during three stages (development, and mid-season and late season) leads to yield reduction of $54 \%$ as compared to fully irrigated treatment. Furthermore, both development and mid-season stage are seen as most sensitive growth stage among others. It is not advisable to skip irrigation during these two stages as it significantly decreased common bean yield. Therefore, one can impose the moisture stress during initial and late season in irrigated agriculture around Jimma, whenever irrigation is limited. 


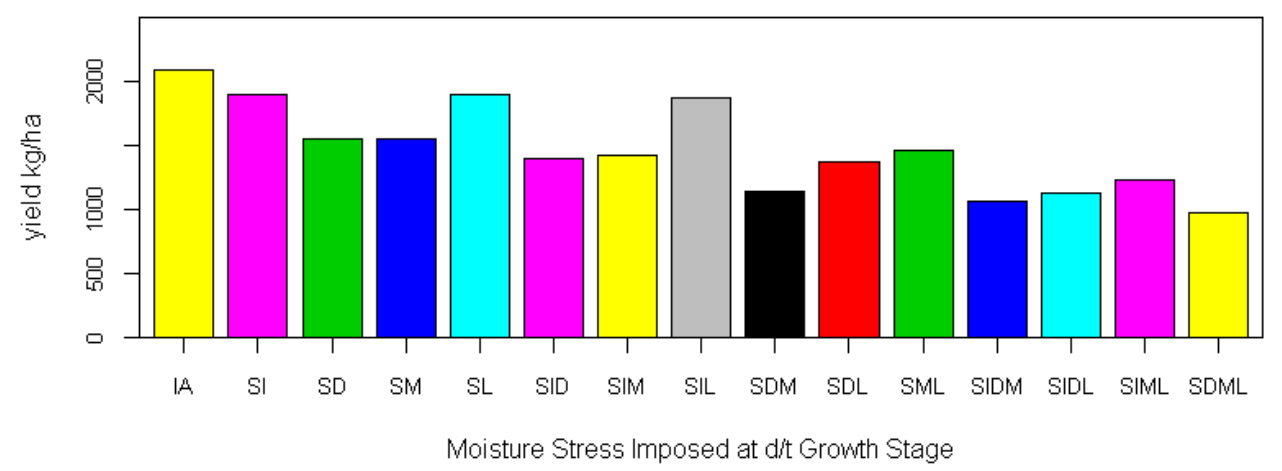

Figure 3: Effect of moisture stress at different growth stage on yield and water productivity

\subsection{Integrated use of Mulching and Furrow irrigation Methods on tomato yields}

Recent study conducted by Robel and Zalalem (2019) at Haru (western Wollaga) indicated that it is possible to increase tomato yield by about $58 \%$ under conventional furrow combined with plastic mulching as compared to fixed furrow without mulch. Maximum marketable yield was recorded from conventional furrow irrigation methods $(43617.3 \mathrm{~K}$. g ha-1) whereas, the minimum yield (24644.2 k.g ha-1) obtained from fixed furrow irrigation method. From the result, the maximum marketable yield recorded from conventional furrow was statistically superior to that of alternative and fixed furrow irrigation method. Concerning the effect of mulches applied, there is a highly significant among them.

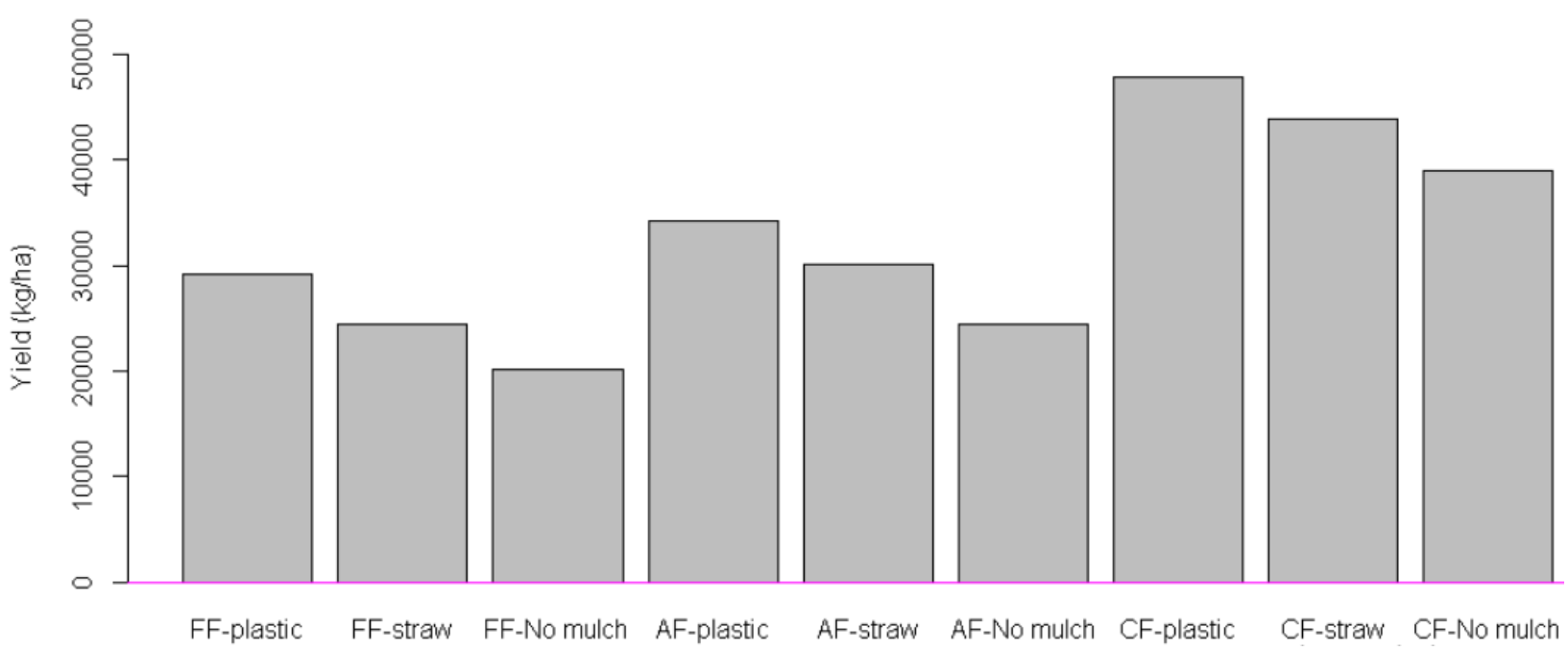

Figure 4: Effect of irrigation and mulching material on tomato yield

\subsection{Yield response of crops to soil moisture depletion level}

FAO conducted varies field experiments under varies agro-ecological zones to set the depletion factor of different crops including soybean. They published the depletion factor for humid, sub-humid and semi-arid areas of the world (Allen et al., 1998). However, the value of depletion factor available in FAO paper is more general and requires some adjustment to the local condition.

To validate such results few studies conducted in Ethiopia, Robel et al. (2019) conducted an experiment for three consecutive years at Jimma, with the aim of determining soil moisture depletion level for soybean crop. They reported that high soybean yield was found in the range of $80-120 \%$ ASWDL. But higher yield was obtained from recommended FAO treatment. From the result they concluded that more frequent irrigation did not increase the yield rather encouraged the vegetative growth of soybean. The demerit of frequent irrigation is loss of water and increase labor cost for water application. Therefore, the optimum soil depletion level for soybean was 100 ASMDL $(p=0.5)$ in irrigated agriculture around Jimma zone.

For optimizing crop production per unit area and for sustaining irrigated agriculture, proper knowledge on time to irrigate and amount of water apply is essential. For reducing the wastage of irrigation water, reducing evaporation loss, reducing leaching below the root depth, allowing crops to exploit the water stored within the soil profile, reducing the accumulation of salts within the soil profile should be an objective. Those objectives can be met, at least partially, by reducing the total irrigation water applied (Greenwood et al., 2009). Where 
water is the limiting factor for crop production, maximizing water productivity by deficit irrigation is often economically more profitable for the farmer than maximizing yield (Demelash, 2011).
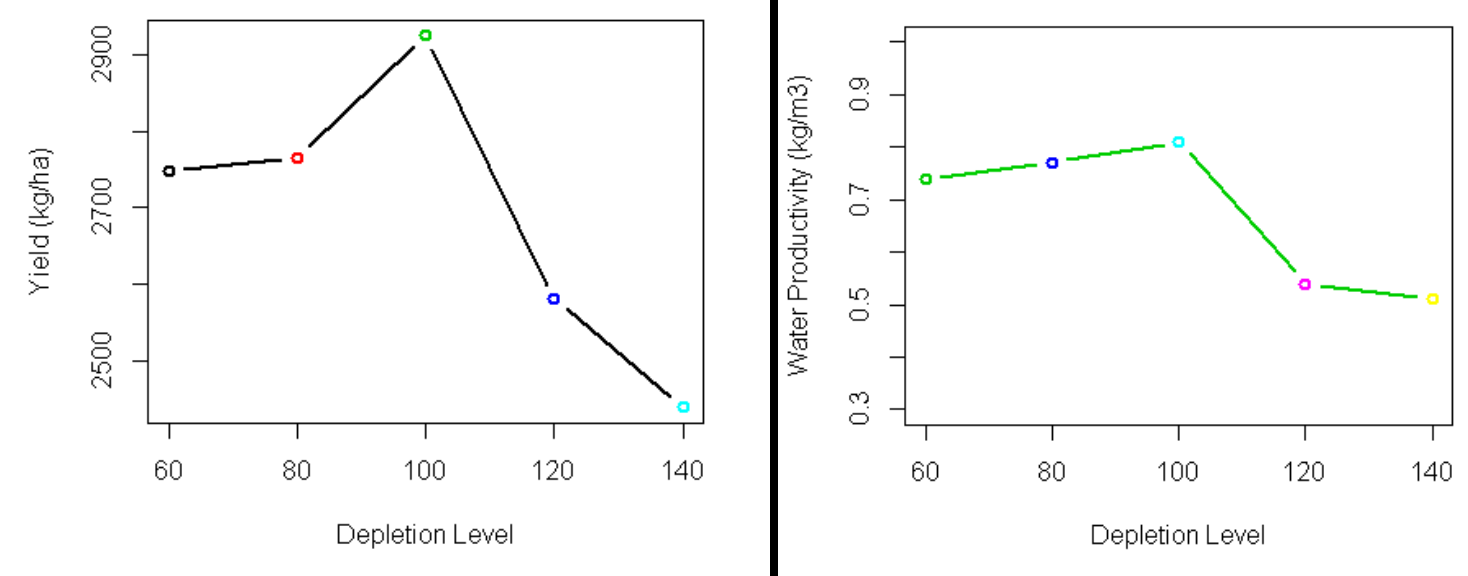

Source: Robel et al., 2019

Figure 5. Effect of soil moisture depletion on soybean yield and water productivity

\subsection{Nitrogen Fertilizer and Deficit Irrigation}

\subsubsection{Yield and WUE response of maize to Nitrogen fertilizer and deficit irrigation}

This experiment was designed to see the response of Soybean to optimum rate of $\mathrm{P}$ and deficit irrigation levels. The result showed that, there was significant difference between treatments of irrigation levels and phosphorus levels for yield. The interactions of phosphorous and irrigations were significant at $5 \%$ probability level for yield. The application of $100 \%$ ETc irrigation level significantly increased yield of soybean. However, application of $50 \%$ ETc irrigation level significantly reduced the yield of soybean. Application of $92 \mathrm{~kg}$ ha-1 phosphorous provided highest yield of soybean than control $(0 \mathrm{~kg}$ ha-1) treatment. Application of $92 \mathrm{~kg}$ ha- 1 nitrogen fertilizer at 100 ETc irrigation level provided highest yield of soybean (JARC, 2020).

\subsubsection{Phosphorus fertilizer and deficit irrigation}

It was investigated that the yield of soybean grown under field condition that treated with varies deficit levels and phosphorous levels were significantly affected. The increase in soybean yield was reported when the level of $\mathrm{P}$ raised from 0 to $46 \mathrm{~kg} / \mathrm{ha}$ and irrigated at $100 \% \mathrm{ETc}$ level at Malko/Jimma / condition, but increasing fertilizer level beyond this cannot increase the soybean yield (JARC, 2020).
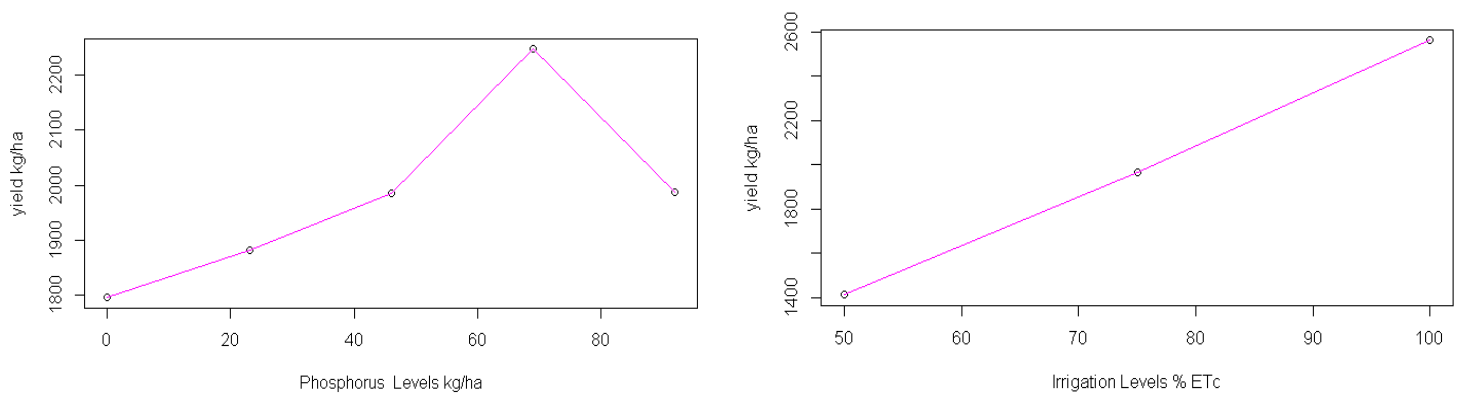

Figure 6: Effect of phosphorus and irrigation levels on yield of soybean

\section{Summary and Conclusion}

In summary, several researchers investigated a lot of irrigation information as well as technologies. Having these technologies various annual crop yield and water use efficiency were improved. Among sound information technologies, deficit irrigation is water saving irrigation strategy, which is good when deficit level is less than $40 \%$. Interestingly, both $100 \%$ ETc alternate furrow and conventional furrow $75 \%$ ETc save extra water with little yield reduction, especially alternate furrow $100 \%$ ETc saves $50 \%$ irrigation water as compared to conventional $100 \%$ ETc. The saved water can be used to irrigate extra unit of land in which additional soybean produce boosting the overall productivity by about $94 \%$ compared to conventional $100 \%$ ETc. Thus, it is advisable to use $100 \%$ ETc alternate furrows in areas with limited water or during dry period even in humid 
areas. Appling irrigation water throughout the whole season reduced the water productivity.

Similar to deficit irrigation, imposing moisture stress across different crop growth stages provided immense advantage. Withholding irrigation during development and mid-season stage (tesseling and silking) had greatly reduced the yield and dry biomass by about 35 and 40\%, respectively. However, imposing moisture stress during initial and late season stage had less impact on yield. The FAO $\mathrm{p}$ factor is more general and not site specific, require adjustments, though the research conducted at JARC revealed that the FAO $\mathrm{p}$ factor (100\% ASMDL) provided highest soybean yield. This implies, that more frequent irrigation did not increase the yield rather encouraged the vegetative growth. Therefore, the optimum soil depletion level for soybean was $100 \%$ ASMDL $(\mathrm{p}$ [depletion factor] $=0.5$ ) for irrigated agriculture around Jimma zone.

\section{Gaps and Way Forward}

Finally, the future research direction should focus on generating water saving technologies and practices together with optimized fertilizer application either through granular or fertigation through liquid water. In addition, the irrigation research should need to be integrating with water harvesting in areas with limited water source either physical or economical.

\section{Reference}

Morison, J.I.L., Baker, N.R., Mullineaux, P.M. and Davies, W.J., 2008. Improving water use in crop production. Philosophical Transactions of the Royal Society B: Biological Sciences, 363(1491), pp.639-658.

Admasu, R., Asefa, A. and Tadesse, M., 2019. Effect of Growth Stage Moisture Stress on Common Bean (Phaseolus Vulgaris L.) Yield and Water Productivity at Jimma, Ethiopia. International Journal of Environmental Sciences \& Natural Resources, 16(1), pp.25-32.

Allen, R.G., Pereira, L.S., Raes, D. and Smith, M., 1998. FAO Irrigation and drainage paper No. 56. Rome: Food and Agriculture Organization of the United Nations, 56(97), p.e156.

Admasu, R., Asefa, A. and Tadesse, M., Determination of Optimal Irrigation Scheduling for Soybean (Glycine max L.) Yield and Water Productivity at Jimma, South West Ethiopia.

Jonghan K. and G. Piccinni (2009). Corn yield responses under crop evapotranspiration-based irrigation management. ELSEVER agricultural water management 96 (2009)799-808

Simsek M., N. Comlekcioglu and I. Ozturk (2011). The effects of the regulated deficit irrigation on yield and Journal of Biology, Agriculture and Healthcare

Enciso J., B. Wiedenfeld, J. Jifon, and S. Nelson (2009). Onion yield and quality response to two irrigation scheduling strategies. ELSEVER Scientia Horticulturae 120 (2009) 301-305

Kang S., Z. Lianga, Y. Panb, P. Shic and J. Zhangd (2000). Alternate furrow irrigation for maize production in an arid area. Agricultural Water Management, 45:267-274

JARC,2019. Annual progress report, Jimma agricultural research center

Zhang, J., S. Kang, Z. Liang., Y. Z. Pan, P. Shi, Y. H. Pan, Z. S. Liang, X. T. Hu. 2000. Soil water distribution, uniformity and water use efficiency under alternate furrow irrigation in arid areas. Irrigation Science 19: 181-190

Stone, J.F., J.E. Garton, B. B. Reeves and H.E. Keflemariam. 1979. Irrigation water conservation using widespaced furrows. Soil Sci. Am. J., 43: 407-411 